\title{
Achondrogenesis type I
}

\author{
A familial subvariant? \\ I. LAUDER, H. A. ELLIS, T. ASHCROFT, and ALICE BURRIDGE \\ From the Departments of Pathology and Radiology, University of Newcastle upon Tyne, \\ Royal Victoria Infirmary, Newcastle upon Tyne
}

\begin{abstract}
Lauder, I., Ellis, H. A., Ashcroft, T., and Burridge, A. (1976). Archives of Disease in Childhood, 51, 550. Achondrogenesis type I: a familial subvariant? The clinical, pathological, and radiological features of 2 male sibs with a severe and lethal form of micromelic dwarfism are described. The family also includes 2 normal sibs. The histological and radiological appearances suggested a diagnosis of achondrogenesis type I, but the markedly deficient ossification of the skull and the presence of intrauterine rib fractures were atypical. These changes have been observed in two other families with 2 or more infants with suspected achondrogenesis, raising the possibility that these familial cases may be a subvariant of achondrogenesis or even a distinct disease entity. The disease appears to be inherited as an autosomal recessive and death occurs shortly after birth because of severe pulmonary hypoplasia.
\end{abstract}

Achondrogenesis is a rare lethal form of congenital micromelic dwarfism in which there is a defect in endochondral ossification. It has only recently been distinguished from other forms of micromelic dwarfism, such as thanatophoric dwarfism, and it is thought to be an autosomal recessive condition (McKusick, 1971). The term achondrogenesis was first used by Fraccaro (1952) though the condition had been recognized some 16 years earlier by Parenti (1936). This lethal form of achrondrogenesis is now designated as achrondrogenesis type I, to distinguish it from a similar but quite distinct disorder described by Grebe (1952). This latter disorder is now known as achondrogenesis type II and is characterized by markedly shortened limbs, tiny digits, and a normal head and trunk. Although over 40 cases of type I have now been described (Wiedemann et al., 1974), only three previous families with 2 or more affected infants have to our knowledge been reported. It is apparent that most of the familial cases do differ from the sporadic cases and it is possible they may represent a similar but distinct disease entity. We report here the clinical radiographic and pathological features of 2 affected male infants in a family which includes 2 other normal male children.

Received 7 October 1975.

^Present address: Department of Pathology, Leighton Hospital, Crewe, Cheshire CW1 4QJ.

\section{Case reports}

The mother was born in 1936 and her height is 152 cm. There is no family history of skeletal abnormalities or consanguinity. The first pregnancy began in August 1963. No fetal movements were noted throughout pregnancy and in February 1964 she was admitted for investigation after developing hydramnios. $X$-ray of the fetus in utero was taken and the radiological features are given below. Shortly afterwards at 28 weeks' gestation she went into spontaneous labour with a vertex presentation and was delivered of a male infant with gross micromelic dwarfism. Regular respirations were never established and the baby died one hour after birth. The cause of death was thought to be pulmonary hypoplasia.

In 1965 and in 1969 she gave birth to normal male infants, both of whom are alive and well. In 1966 she had a spontaneous abortion at 8 weeks' gestation, and in 1968 she aborted a male fetus weighing $900 \mathrm{~g}$ at 25 weeks' gestation, which showed no external abnormalities. Post-mortem examination was not performed.

The sixth and final pregnancy began in December 1971. The uterus was noted to be large for dates and this was thought to be due to an excess of liquor. In August 1972 at 32 weeks' gestation she had a painless antepartum haemorrhage which settled soon after admission. There was no evidence of placenta praevia but she had a persistent slow loss of liquor until she went into spontaneous labour at 33 weeks' gestation. After a breech delivery she gave birth to a male infant weighing $1840 \mathrm{~g}$ with gross micromelic dwarfism. Regular respirations were never established and the baby died 10 minutes after birth. 
Radiological findings. Films from the first child were no longer available but were reported at the time as showing a single fetus, small-for-dates because of defective ossification of the skeleton. The skull was barely visible and a provisional diagnosis of hypophosphatasia was made. Radiographs were only available for inspection on the second infant, and are shown in Figs. 1 and 2.

There was gross deficiency of mineralization of the vault of the skull with almost complete lack of ossification of the parietal bones. The size of the vault was proportional to the size of the facial bones. The latter were more mineralized than the vault; the symphysis menti was unfused. There was complete absence of ossification of the vertebral bodies throughout the spine. Ossification centres for the pedicles and neural arches

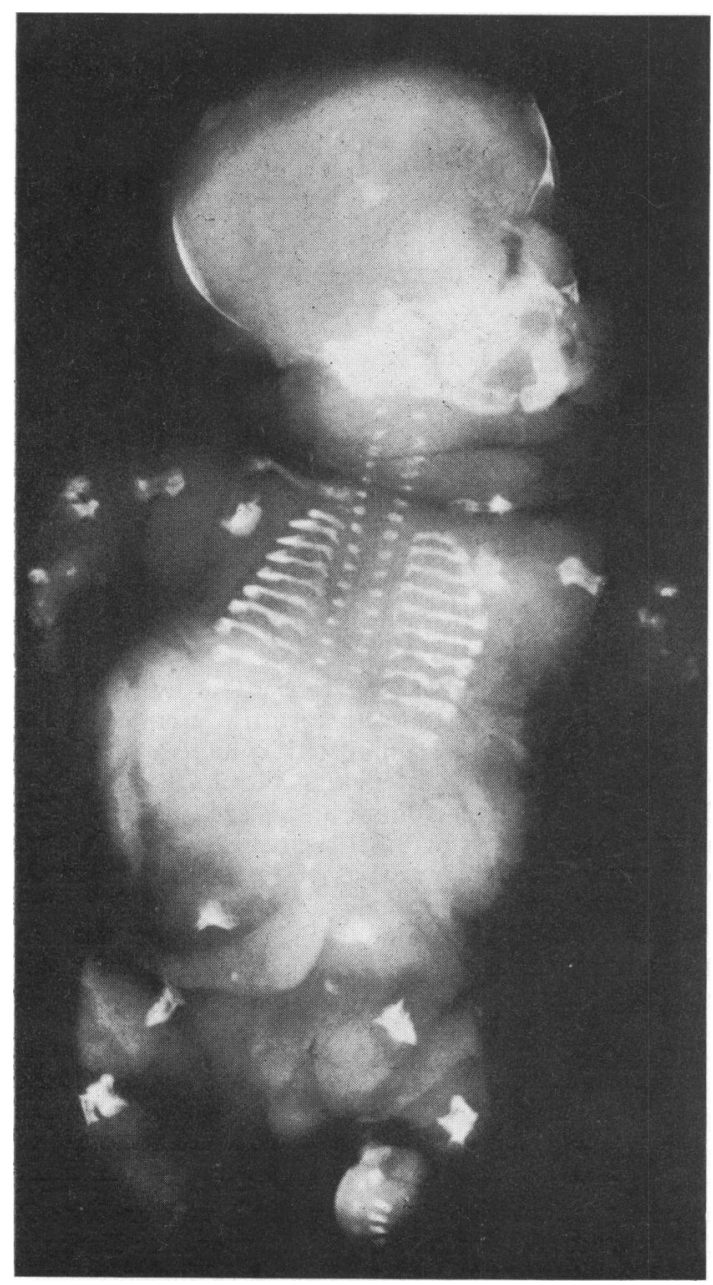

FIG. 1.-Case 2. Radiograph showing gross undermineralization of the skull vault and the vertebral bodies in a micromelic dwarf. Note intrauterine rib fractures. were present from the cervical region to $S 1$. The other sacral segments were not represented on the radiograph.

There were 12 pairs of narrow short ribs, all of which showed cupping of the costochondral junction. Many of them had defects suggestive of intrauterine fractures with callus formation. The defects occurred at various sites along the length of the rib. The sternum was completely unossified. In the pelvis two small very irregular centres for the ilia were present. No ossification centres for the pubis were identified and there were 'dot' centres representing the ischia.

In the upper limb the clavicles were of normal length and ossification. The centres for the scapulae were irregular and wide (the same as the centres for the ilia) but small compared with the normal of the same gestational age. The tubular bones of the upper limb were all small, and showed flaring of the metaphysis (relative sizes, humerus $13 \mathrm{~mm}$, forearm bones $7 \mathrm{~mm}$ ). Short flared metacarpals were present in the hand. No centres were present in the carpus but all phalanges were present. In the lower limb the femur was short and irregular with marked flaring of the upper metaphysis and slight lateral bowing. The bone measured $10 \mathrm{~mm}$. The tibiae and fibulae measured $9 \mathrm{~mm}$ each and were stunted, with pronounced flaring of the lower metaphysis. A single centre represented the tarsus. The metatarsals were all ossified and were short and flared, the proximal phalanges were all present but middle phalanges were only present for the first and second toes.

In summary the most striking radiological features were (1) gross underossification of the cranial vault; (2) complete lack of ossification of the vertebral bodies throughout the spine; the sternum was also unossified; (3) ossified but stumpy limb bones showed cupping of the metaphyses; (4) short narrow ribs with intrauterine fractures, cupped costochondral junctions, and splayed heads.

\section{Post-mortem findings.}

First affected infant. The external appearances are shown in Fig. 3. The most striking feature was the gross symmetrical shortening of the arms and legs. Crown-rump length was $24 \mathrm{~cm}$; crown-heel length $28 \mathrm{~cm}$. The arms and legs were all about $5 \mathrm{~cm}$ in length. The head was large in relation to the rest of the body and because the neck was not obvious externally, the head appeared to sit directly on the shoulders. The abdomen was protuberant and the umbilical cord was normal. Prominent skin creases on the arms and legs appeared to be due to an excess of soft tissue relative to the shortness of the limbs. Knee and elbow joints could not be clearly identified externally.

Internal examination of the viscera showed a persistent ductus arteriosus and marked pulmonary hypoplasia. Both lungs were atelectatic and sank immediately on immersion. The ribs were markedly shortened and nearly all showed evidence of intrauterine fractures with callus formation. There was mild hydronephrosis and hydroureter on both sides and the testes had not descended from the abdominal cavity. The brain 


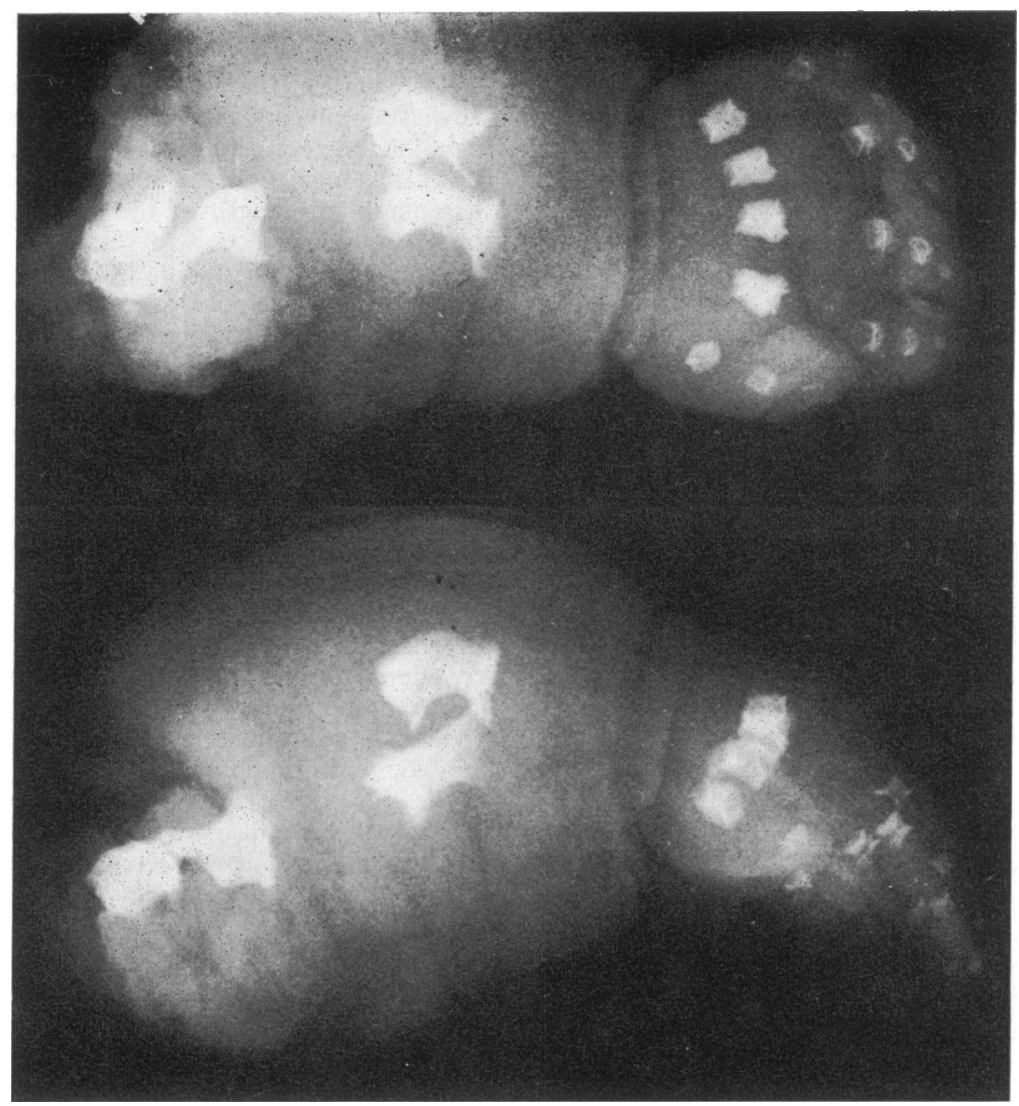

Fig. 2.-Radiograph of fetal upper limb showing gross shortening of the bones and metaphyseal flaring.

showed numerous subependymal haemorrhages in the lateral ventricles and subarachnoid haemorrhage over the left parietal lobe and the cerebellum.

The vault of the skull consisted mostly of membrane with only very small foci of ossification in the frontal and parietal bones in each side. The vertebral bodies consisted almost entirely of cartilage and there was an excess of cartilage at the costochondral junctions. In the leg bones there was minimal ossification of the diaphyses with a gross excess of cartilage at the epiphyseal ends. As the microscopical appearance of the bone was similar in both cases it is described jointly in the details of the second case.

Second affected infant. The external appearance of the second case was very similar to that described for the first (see Fig. 4). Crown-rump length was $26 \mathrm{~cm}$ and the crown-heel length $29.5 \mathrm{~cm}$. The arms measured $5 \mathrm{~cm}$ in length and the legs $6 \mathrm{~cm}$.

Internal examination showed recent haemorrhage in relation to the tentorium cerebelli and falx cerebri, a persistent ductus arteriosus, and gross pulmonary hypoplasia (see Fig. 5). Detailed examination of the lungs of the second infant was carried out by Dr. Alison Hislop at the Cardiothoracic Institute, London. The lungs showed a total uninflated volume of $5.5 \mathrm{ml}$, equivalent to an uninflated lung of an 18-week fetus. The expected inflated volume at this age is $40 \mathrm{ml}$. The airway to the posterior basal segment of the left lower lobe was dissected and a serial reconstruction made. The airways were abnormally small and too few since there were only 17 generations to the terminal bronchioles. The airway structure was normal, in particular the cartilage plates.

Histology. In the long bones the most striking feature was a gross deficiency in endochondral ossification. In the first case there was none and in the second it was grossly deficient. The bones were represented by cartilaginous 'models' similar to those encountered normally in fetuses of about 12 weeks' gestation (Fig. 6). The only ossification was at the centre of the diaphysis where the bone usually appeared to arise metaplastically directly from the cartilage or in some areas from connective tissue (Fig. 7). In some areas much of the bone was formed in relation to the periosteum and in these 


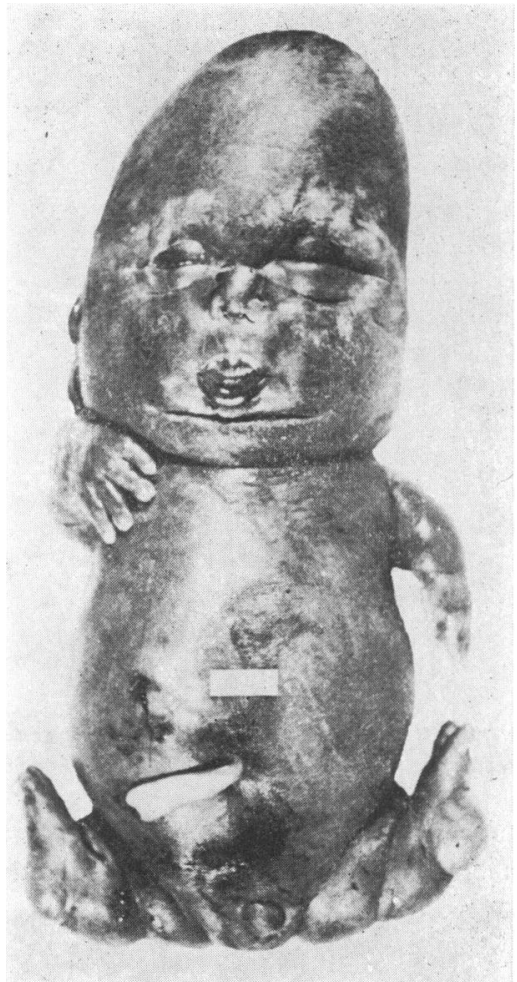

Fig. 3.-Case 1. External features.

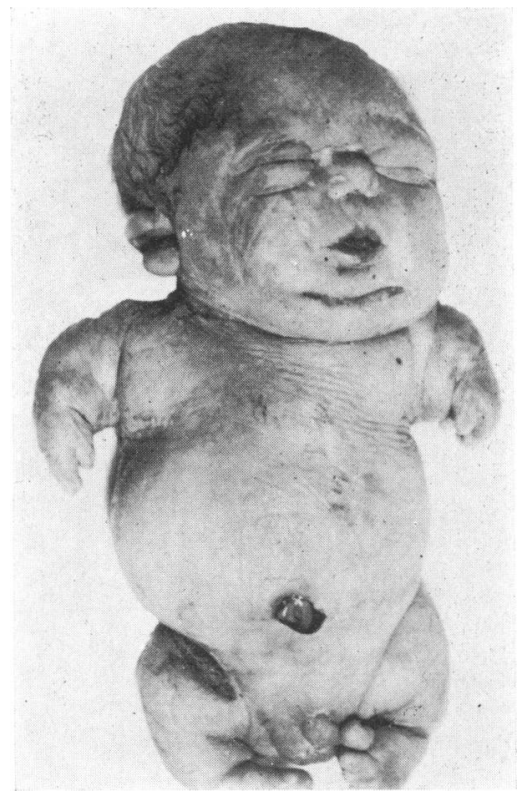

FIG. 4.-Case 2. External features.

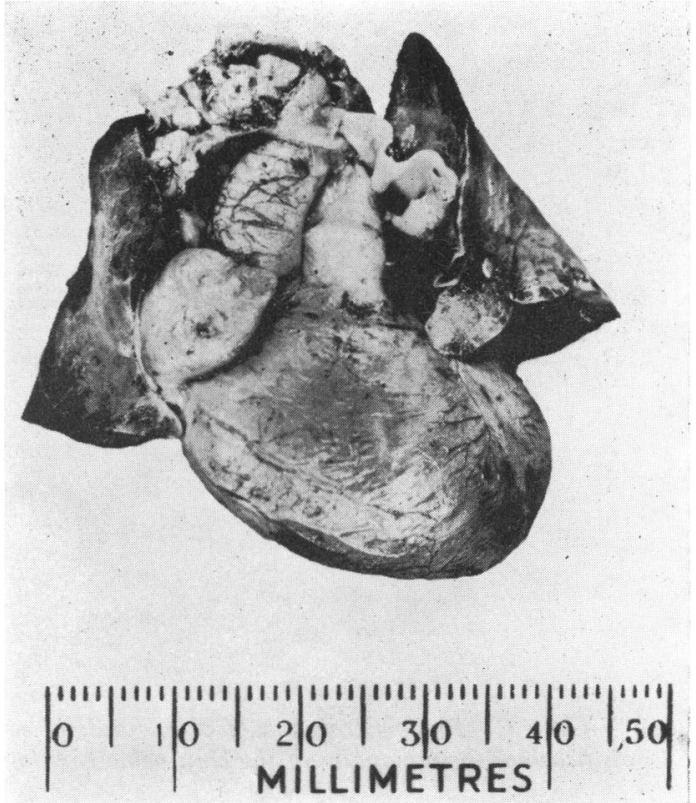

Fig. 5.-Case 2. Thoracic organs showing gross pulmonary hypoplasia.

areas there was intense osteoblastic activity. There was some evidence of endochondral ossification in the second case but this was grossly irregular and there were no clearly defined zones of proliferation, hypertrophy, or calcification (Fig. 8). The cartilage itself in both cases appeared abnormal. When compared with control tissue from a fetus of the same gestational age (Fig. 9), the chondrocytes were much larger with large nuclei and had a greater tendency to be arranged in groups of two or more cells. The increase in size of the cells was sufficient to reduce markedly the amount of intercellular matrix. The latter, however, showed a normal metachromatic reaction.

Where ossification did occur the bone consisted almost entirely of woven bone and only the second case showed a few small foci of lamellar bone formation. Cement lines were irregular but undecalcified sections showed normal mineralization with no excess osteoid. The only osteoid apparent was present in the periosteal region of the humerus of the second case. Joint spaces were very poorly formed. Rudimentary joint clefts were identified at the elbow and knee joints but none was apparent in the hands and feet. Both the knee and elbow joint clefts contained a small amount of fibrin (Fig. 10). Virtually no myeloid tissue was present in the axial or appendicular skeleton of the first case, but in the second case the small amount of myeloid tissue was intensely cellular. There was some increase in the vascularity of the metaphyses in both cases. Alkaline phosphatase activity was stained in unfixed sections 


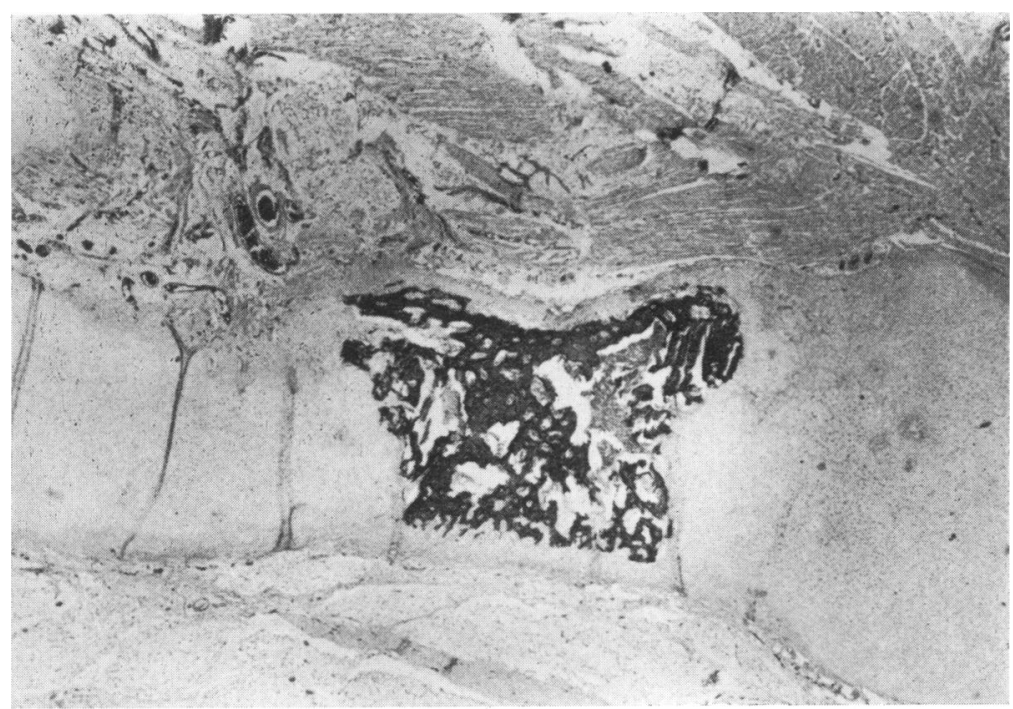

FIG. 6.-Case 1. Photomicrograph of a longitudinal section of a metatarsal bone. Note the mid-diaphyseal zone of ossification, the remainder of the bone being cartilaginous. (Undecalcified, haematoxylin and eosin.

$\times 10$.)

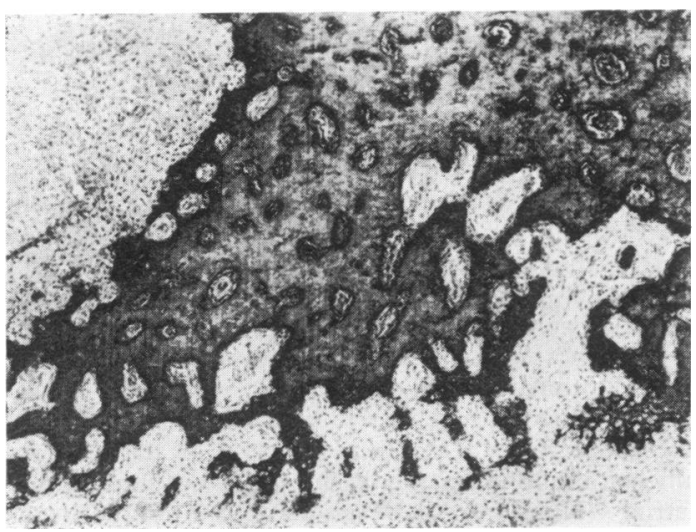

FIG. 7.-Case 1. Photomicrograph of ossifying zone in the femoral diaphysis, showing woven bone formation in cellular fibrous matrix. (Undecalcified section, haematoxylin and eosin. $\quad \times 40$.)

(Burstone method). The test was strongly positive (Fig. 11) in osteoblasts.

Most of the calvarium consisted of collagenous connective tissue. Where ossification did occur there were again irregular cement lines, normal mineralization in

FIG. 8.-Case 2. Photomicrograph of a rare zone of endochondral ossification in the lower end of the humerus. Note the woven bone (top left) and irregular cartilage with disordered endochondral ossification (centre and right) and a rare focus of cellular marrow. (Decalcified section, haematoxylin and eosin. $\times 38$.) undecalcified sections, and there was only woven bone. The vertebral bodies showed no ossification and con-

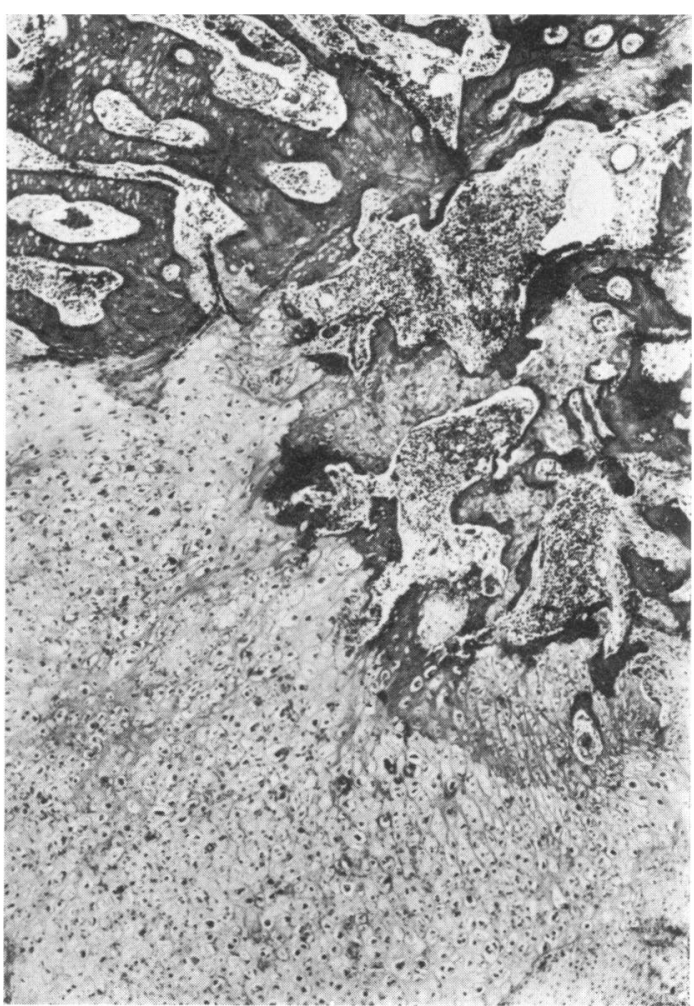




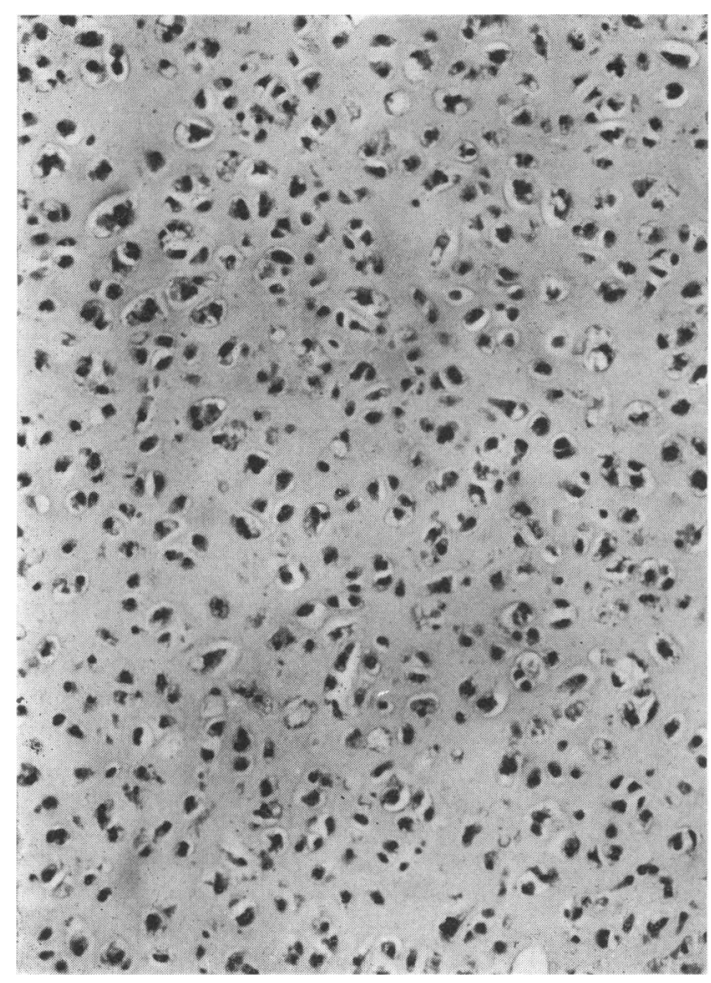

FIG. 9.-Case 1. Photomicrograph of upper end of femur showing abnormal cartilage. (Decalcified section, haematoxylin and eosin. $\times 150$.)

sisted of abnormal cartilage similar to that seen in the long bones. The ribs likewise showed abnormal cartilage but there was intense osteoblastic activity at the sites of intramembranous ossification.

Histological examination of the lungs showed that the alveolar region was inactive and was still in the canalicular stage. Alveoli could not be identified and a considerable amount of mesenchyme was present. The number of air spaces in an acinus seemed less than normal for age. No hyaline membrane was seeen. The arteries appeared thicker walled than normal in a fetus and the veins were more muscular than expected. Neither of these vascular changes was extreme. No air was present in any of the pulmonary acini.

In both cases there was very marked extramedullary haemopoiesis. The brain of the first case showed numerous small intracerebral haemorrhages in the proximity of the ventricles. The thymus showed normal corticomedullary differentiation and in the first case formation of Hassall's corpuscles seemed unusually well advanced. A feature of both cases was fairly generalized vascular congestion, and the heart of the second case showed subepicardial petechial haemorrhages. The placenta of this case was also examined

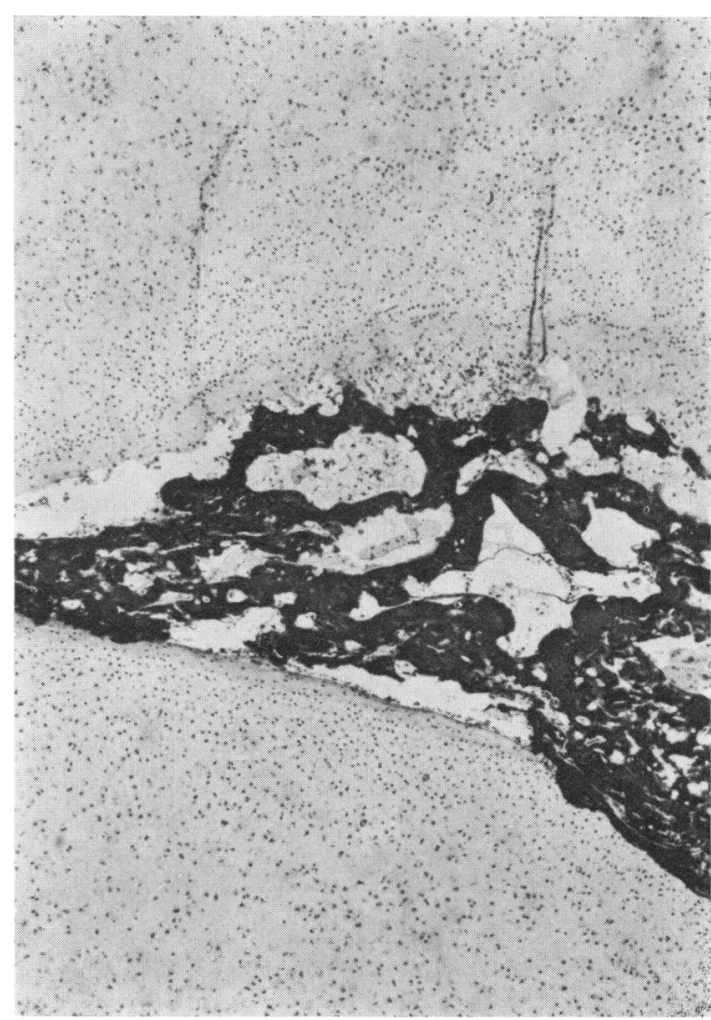

FIG. 10.-Photomicrograph of rudimentary elbow joint cleft containing dense strands of fibrin (dark) with pale 'articular' cartilage each side. (Decalcified section, haematoxylin and eosin. $\times 39$.)

and it too showed dilatation and congestion of fetal blood vessels and foci of intervillous thrombus.

\section{Discussion}

The published reports on achondrogenesis have recently been reviewed by Wiedmann et al. (1974) who cited 37 cases now thought to represent achondrogenesis, though many of these were only diagnosed retrospectively. Several cases have been poorly documented, casting grave doubt on whether all the cases had been adequately distinguished from similar skeletal disorders such as thanatophoric dwarfism, hypophosphatasia, and homozygotic achondroplasia. Wiedemann et al. (1974) described 6 further cases and even one of these was regarded as unproved. There have been only 3 previous accounts of affected sibs excluding the personal communication of Silverman (1971) cited by McKusick (1971). Houston described a family of 10 children of whom 4 had been born 


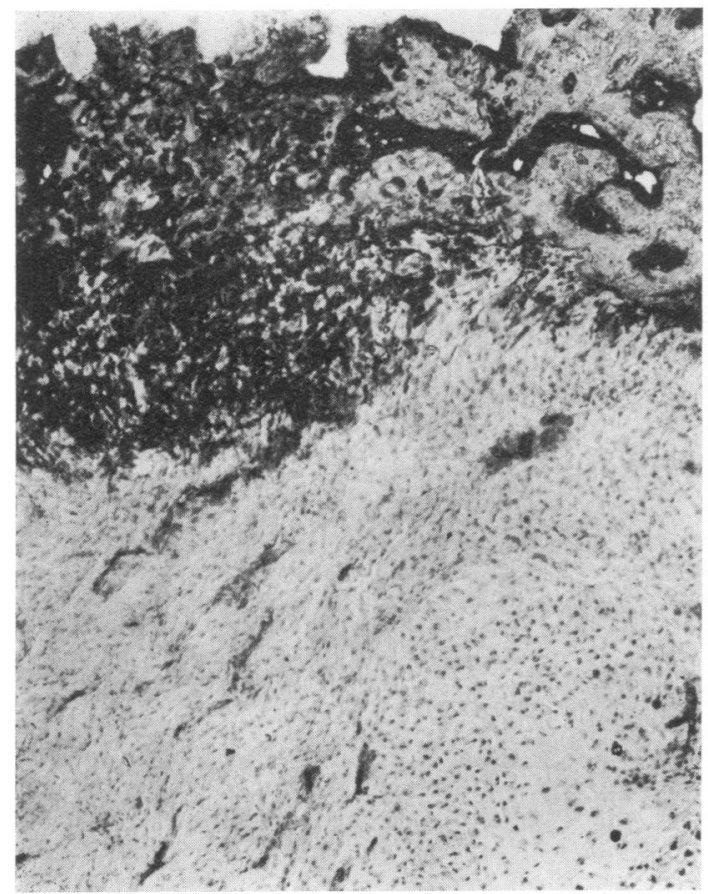

(a)

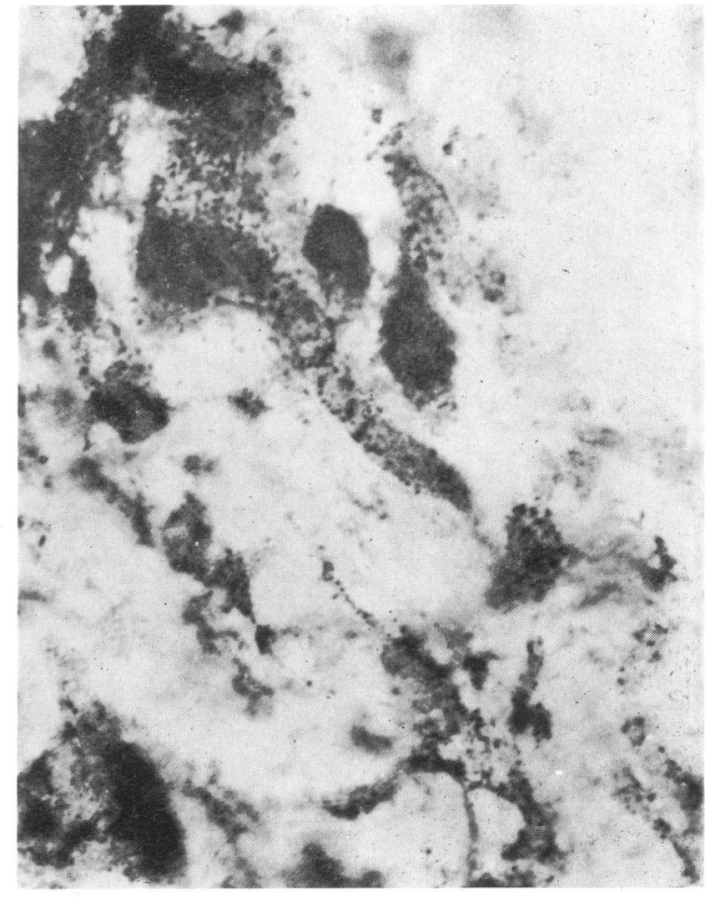

(b)

Fig. 11.-Photomicrographs of the margin of a zone of limb bone ossification showing alkaline phosphatase activity. (a) Low power with intense staining in bone-forming connective tissue and at margins of woven bone trabeculae (top right). (b) Higher power showing localization of enzyme activity to individual connective tissue cells. (Undecalcified, frozen section, Burstone's method. $($ a $) \times 60 .($ (b) $\times 1000$.)

prematurely with fatal deformitits which were thought to be due to achondrogenesis (Houston, Awen, and Kent, 1972). They were able to exclude hypophosphatasia by enzyme and other biochemical studies in the remaining members of the family. In the family described by Harris, 2 out of 3 children were affected by a fatal skeletal abnormality for which they used the term pseudoachondrogenesis (Harris, Patton, and Barson, 1972). This term was used because they considered the radiological features and the presence of pathological rib fractures were not typical of the classical type of achondrogenesis as described by Saldino (1971). The latter described a gypsy family with 2 affected infants and 2 normal sibs. In their cases ossification of the skull was relatively normal and there was no mention of rib fractures. The presence of intrauterine rib fractures with abundant callus formation and the defective ossification of the skull are the main features which distinguish most cases of familial achondrogenesis from the much more common isolated cases. In addi- tion the shortening and distortion of the long bones is more extreme.

The main differential diagnosis is fetal hypophosphatasia. We suggest that the presence of normal amounts of osteoblastic alkaline phosphatase shown in one of these cases effectively eliminates this possibility. In addition, the degree of shortening of body length and the severity of the micromelia is more marked than that reported in hypophosphatasia. The primary defect in achondrogenesis is a gross inadequacy or absence of endochondral ossification and if undecalcified sections are examined, as in this study, then mineralization is apparently normal. As Wiedemann et al. (1974) point out, many of the previous studies of achondrogenesis have failed to look at undecalcified material and no conclusion as to the degree of mineralization is justified after decalcification.

Most other features of achondrogenesis were present in both of our cases. As observed by other authors both cases exhibited polyhydramnios during pregnancy, though the cause of this is un- 
explained. Both radiologically and histologically there was grossly deficient ossification of all limb bones, the ribs, and characteristically of the disease, the vertebral bodies. The radiological evidence of defective ossification of the sacrum, pubic and ischial bones is also fairly typical. The abnormal appearance of the chondrocytes, defective endochondral ossification, gross excess of woven bone, and the poorly formed joint clefts are all similar to the changes described by Wiedemann et al. (1974). We have been unable to confirm their observation about decreased metachromasia in the ground substance of the bone. Some of the histology in their cases was prepared after prolonged fixation, whereas in our cases we have examined sections prepared only a few days after death. Apart from the possibility of technical artefact it is also possible that in these familial cases normal metachromasia may be a feature of the disease.

If the present 2 familial cases are added to those of Houston et al. (1972), Harris et al. (1972), and Saldino (1971) then there are 10 examples of familial achondrogenesis with 7 affected male infants and 3 females. Within the 3 families there were 11 unaffected infants and the presence of 10 affected infants with no other known affected members of the family in previous generations suggests an autosomal recessively inherited genetic defect. Death occurs soon after birth because of the severe degree of pulmonary hypoplasia secondary to the shortening of the ribs. It seems likely that the defect is primarily in the mesenchymal skeletal tissue but its precise nature remains unclarified. Further detailed pathological, biochemical, and radiological studies in many more cases are re- quired before it will be possible to determine why the familial cases differ from the classical sporadic cases. It is possible that as Harris et al. (1972) suggest these cases may represent a different disease for which their term 'pseudoachondrogenesis with fractures', may be more appropriate.

The help of Dr. Alison Hislop of the Department of Experimental Pathology, Cardiothoracic Institute, Fulham Road, London, is gratefully acknowledged. We also wish to thank Dr. Edmund Hey, the Hospital for Sick Children, Great Ormond Street, for his help and encouragement.

\section{REFERENCES}

Fraccaro, M. (1952). Contributo allo studio delle malattie del mesenchima osteopoietico: l'acondrogenesi. Folia hereditaria et pathologica, 1, 190.

Grebe, H. (1952). Die achondrogenesis, ein einfach rezessives Erbmerkal. Folia hereditaria et pathologica, 2, 23.

Harris, R., Patton, J. T., and Barson, A. J. (1972). Pseudoachondrogenesis with fractures. Clinical Genetics, 3, 435.

Houston, C. S., Awen, C. F., and Kent, H. P. (1972). Fatal neonatal dwarfism. Fournal of the Canadian Association of Radiologists, 23, 45.

McKusick, V. A. (1971). Mendelian Inheritance in Man, p. 298. Johns Hopkins Press, Baltimore and London.

Parenti, G. C. (1936). La anosteogenesi (una varietà della osteogenesi imperfetta). Pathologica, 28, 447.

Saldino, R. M. (1971). Lethal short-limbed dwarfism: achondrogenesis and thanatophoric dwarfism. Americal fournal of Roentgenology, Radium Therapy and Nuclear Medicine, 112, 185.

Silverman, F. (1971). Personal communication cited by McKusick, V. A. Mendelian Inheritance in Man, p. 299. Johns Hopkins Press, Baltimore and London.

Wiedemann, H-R., Remagen, W., Hienz, H. A., Gorlin, R. J., and Maroteaux, P. (1974). Achondrogenesis within the scope of connately manifested generalized skeletal dysplasias. Zeitschrift fürKinderheilkunde, 116, 223.

Correspondence to Dr. I. Lauder, Department of Histopathology, Royal Victoria Infirmary, Queen Victoria Road, Newcastle upon Tyne NE1 4LP. 